The 3rd International Conference on Biological Science 2013

(The 3rd ICBS-2013)

\title{
INDIVIDUAL HUMAN SERA RESPONSE AGAINST PROTEIN EXTRACTS FROM SALIVARY GLAND OF Aedes aegypti
}

\author{
Rike Oktarianti ${ }^{1,2}$, Kartika Senjarini ${ }^{1}$, Fatchiyah ${ }^{2}$, and Aulani'am ${ }^{3}$ \\ ${ }^{1}$ Department of Biology, Faculty of Mathematics and Natural Sciences, Jember University \\ ${ }^{2}$ Department of Biology, Faculty of Mathematics and Natural Sciences, Brawijaya University \\ ${ }^{3}$ Department of Chemistry, Faculty of Mathematics and Natural Sciences, Brawijaya University \\ Corresponding author: rike.oktarianti@yahoo.com
}

\begin{abstract}
The saliva of hematophagous arthropods contains a complex mixture of biologically active proteins. These proteins may modify hemostatic responses and induce both cellular immunity and the production of specific antibodies, and thus influence the transmission of its pathogens from arthropods vector to human host. Aedes aegypti is the main vector for transmission of dengue viruses into human. The objective of this study was to examine individual human sera response against protein extracts from salivary gland of $A e$. aegyptithat mediate the infection of dengue viruses. We did a cross reaction test of human sera from healthy people in endemic and non-endemic area, and dengue patients againts SGE of $A e$. aegypti to distinguish and to identify the immunogenic proteins using Western Blot Analysis. About 15 protein bands of SGE from Ae. aegypti ranging from $15 \mathrm{kDa}$ up to $255 \mathrm{kDa}$ were identified on $12 \%$ SDS-PAGE. Seven dominant bands were detected, i.e $\sim 255,56,42,31,27,26$ and $15 \mathrm{kDa}$. Two immunogenic proteins, as represented by two bands, i.e. $~ 31$ and $56 \mathrm{kDa}$ were found only in samples from people who were previously exposed to mosquitoes bites, and not in people who had not been exposed. Therefore, these immunogenic salivary proteins may serve as indicators for the immune response in human against protein from salivary gland of Ae. aegypti.
\end{abstract}

Keywords: immunogenic proteins, salivary gland, Aedes aegypti,

\section{INTRODUCTION}

Dengue virus (DV) causes dengue fever and more severe conditions of dengue hemorrhagic fever (DHF) and dengue shock syndrome (DSS). The World Health Organization estimates that there are 50 million dengue infections every year worldwide (Wasinpiyamongkol et al., 2010). DV is transmitted to vertebrate host by mosquito vectors, with Aedes aegypti as the main vector and Aedes albopictus as secondary vector. The vectors acquire the pathogens by feeding on infected hosts and then transmit them by regurgitation during a subsequent blood feeding (Ader et al., 2004). Blood feeding is required for nutrition, egg development and survival of mosquitoes (Gillespie et al, 2000). Mosquito saliva is vital for successful blood feeding because it contains anticoagulant, anti-inflammatory, anti platelet aggregation and immunosuppressive factors (Ribeiro \& Francischetti, 2003). Saliva proteins or salivary gland extracts also have antigenic and immunogenic properties, as they can induce an IgG antibody response in individuals living in endemic areas (Remouse et al., 2007; Waitayakul et al., 2006) and in travellers transiently exposed to vectors in tropical areas (Orlandi-Pradines et al., 2007). These proteins can induce allergic reactions such as itchy and red skin (Fontaine et al., 2011). The development of a natural antibody response in people living in endemic area is due to frequent exposure to mosquito saliva (Cornelie et al., 2007). This indicates that the vector bites have a positive effect on the host immune response. These responses can be used as epidemiological markers of vectors exposure and also support the possibility to prevent and treat allergic responses, and to develop anti-arthropod vaccines (Andrade et al., 2005).

ISSN 2413-0877 (C) 2015 The Authors.

Published by KnowledgeE Publishing Services This is an open access article under the CC BY-NC-ND license (http://creativecommons.org/licenses/by-nc-nd/4.0)

Selection and Peer-review under responsibility of the 3rd ICBS-2013

Doi http://dx.doi.org/10.18502/kls.v2i1.121 
The phenomenon of host immune response against saliva vector has been studied by Donovan et al. (2007) who reported that animal models previously exposed to Anopheles stephensi enhance their immune response and inhibit the development of the parasite in the liver and blood. Their immunity is related to a Th1 immune response, with significant production of interferon (IFN)- $\gamma$, interleukin (IL)-2 and IL-12. In respond to this problem, bloodfeeding arthropods have evolved salivary immunomodulatory factors which prevent host from becoming sensitized to the saliva or even retard deleterious host responses. Such factors induce a Th2 deviation of host's immune response, which favors insect survivor (Andrade et al., 2005). Scheneider et al (2004) reported the opposite results on previous findings of Donovan et al. (2007). Salivary gland extract of $A e$. aegyptiwere co-inoculated with Sindbis virus into mice would increase the immune response toward the Th2 (IL4 and in IL-10 cytokines were increase), whereas the IFN $\chi$ and IFN $\beta$ were significantly decreased. Similar results were reported by Schneider \& Higgs (2008) in which a high concentration of salivary proteins was found to be immmunosuppressive.

In this regard SG proteins of Ae. aegyptimay modify hemostatic responses and induce both cellular immunity and the production of specific antibodies. Therefore, individual human sera response against protein extracts from salivary gland of $A e$. aegypti is important in determining the factors increasing the transmission of pathogen to human host.

\section{MATERIALS AND METHODS}

\section{Rearing of Ae. aegypti and Salivary Gland (SG) Dissection}

Mosquitoes larvae were collected and reared under strictly identical standard conditions of $28^{\circ} \mathrm{C}$ and $60 \%$ relative humidity at Zoology Laboratory, Department of Biology, Faculty of Natural Sciences, Jember University. Mosquitoes were supplied with a cotton wool pad soaked in $10 \%$ sucrose solution. The salivary glands from adult mosquito females were dissected using a fine entomological needle under a stereomicroscope at 4 magnification. Then the salivary glands were pooled into a microcentrifuge tube on ice in phosphate-buffered saline (PBS) and PMSF, then stored frozen at $-20^{\circ} \mathrm{C}$ until needed.

\section{Salivary Gland Protein Extraction}

Salivary glands in PMSF and PBS was added with lysis buffer (1:1). The lysis buffer containing $1.5 \mathrm{mM} \mathrm{MgCl} 2,10 \mathrm{mM}$ tris $\mathrm{HCl}, 10 \mathrm{mM} \mathrm{NaCl}, 1 \%$ Nonidet P-40, $2 \mathrm{mM}$ EDTA $\mathrm{NaOH}$. After being homogenized with micropistile, sonicated in water bath for $30^{\prime}$, then the mixture was centrifuged at $12.690 \mathrm{rpm}$ for $15^{\prime}$ in $4^{\circ} \mathrm{C}$. Supernatant will be concentrated by using eppimembran and centrifuged at $10.000 \mathrm{rpm}$ in $4^{\circ} \mathrm{C}$ by the repeated the procedure for several times so that the concentration becomes more dense, and protein concentration of these salivary gland extract reached $0.69 \mathrm{ug} / \mathrm{ul}$. Salivary gland proteins were then stored at $-20^{\circ} \mathrm{C}$ until used.

\section{Preparation of Blood Sera DHF Patient and Healthy People}

Sera sample from DHF patients were collected from endemic area, while sera from healthy people were collected from both endemic area and non endemic area. All participants were informed for their consent to take part in the study following the protocol ap- 
proved by the Ethical Committee, Faculty of Medicine, Brawijaya University and Jember University.

\section{SDS-PAGE \& Western Blotting}

Total proteins from salivary gland extract were separated by $12 \%$ SDS-PAGE. The gels were stained with commassie brilliant blue (CBB) R-25 to visualize the proteins. Proteins were transferred to a PVDF membrane under constant current (100 MA) for 1 hour by using semidry Western Blotting. The membranes were blocked for 1 hour with $5 \%$ skimmed milk in TBS. Each membrane strip was incubated with a human sera $(1: 500)$ overnight at $4^{\circ} \mathrm{C}$. Membranes were then incubated with secondary antibodies of anti-human IgG antibodies (goat) AP-conjugated (1:5000) for 2 hours on shaker. Color development was done with NBT-BCIP phosphatase substrate. Prestained broad range molecular weight markers of $7-$ 250 kDa (Intron cat 24084, 24085) were used for estimating protein size.

\section{RESULTS AND DISCUSSION}

\section{Salivary Gland of female Ae. aegypti}

The salivary glands of adult female Ae. aegypti have a distinctive tri-lobed structure consisting of a single medial and two lateral lobes (Figure 1). The lateral lobes were divided into two regions, the proximal and distal. The structure of Ae. aegypti salivary gland is in pairs, and connected by salivary duct (Juhn el al., 2011). Their salivary glands produce proteins containing a number of pharmacologically active components that counteract vertebrate hemostasis, and thus allowing the mosquito to feed successfully such as vasodilator, anti-clothing, and anti-hemostatic protein. It plays a role in pathogen transmission and may induce an immune response in vertebrate host (Valenzuela et al., 2002, Cornelie et al., 2007, Waitayakul et al., 2006).

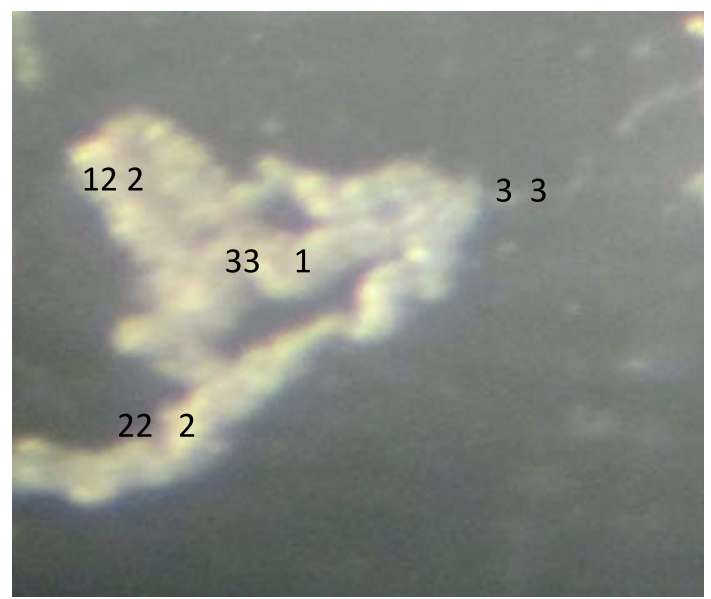

Figure 1. Single salivary gland dissected from a female Ae. Aegypti. The salivary gland is comprised of single medial lobe (1) and two lateral lobes (2), the salivary duct connects all salivary gland lobes (3).

\section{Protein profile of SGE Ae. aegypti}

Identification of protein profile from SGE of Ae. aegypti by using SDS-PAGE showed the occurrence of at least 15 bands with different molecular weight ranging from 15 to 255 
kDa. Seven dominant bands were detected i.e, 255, 56, 42, 31, 27, 26 and 15 kDa (Figure 2). Previous study by Wongkamchai et al (2010) reported that 13 proteins bands were detected from salivary gland of Ae. aegypti with molecular weight ranging from 33.5 to $>88.5 \mathrm{kDa}$. Meanwhile, Machain-Williams et al., (2012) reported seven prominent bands with approximate molecular masses of $68,46,36,30,19,17$, and $14 \mathrm{kDa}$ using by non denaturing PAGE.

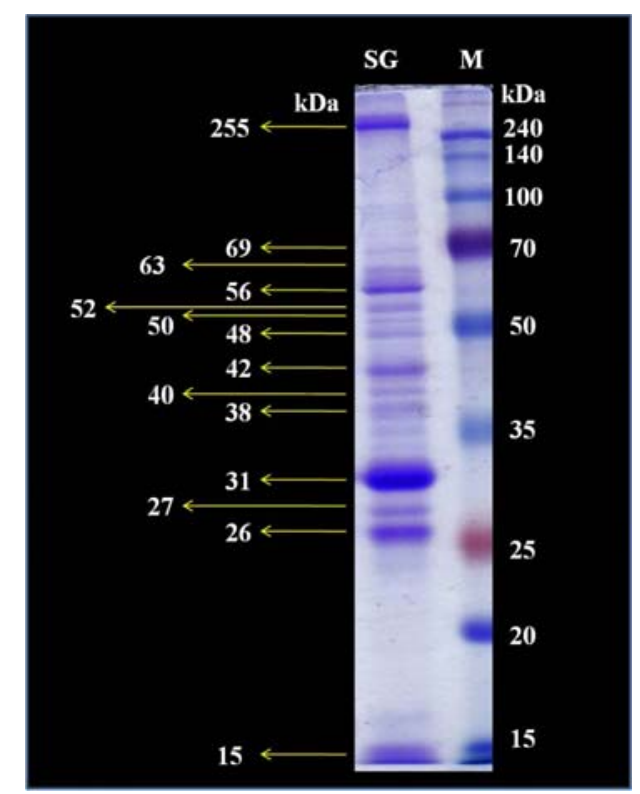

Figure 2. Protein profile of SGE from Ae. aegypti form isolation of 100 pairs SG. (SG) Salivary Gland, (M) marker

\section{Immunogenic Proteins of SGE Ae. aegypti}

Cross reaction test of human sera from healthy people in endemic and non-endemic area, and dengue patients againts SGE of Ae. aegypti to distinguish the response and to identify the immunogenic proteins was done by Western Blot Analysis. Two immunogenic proteins (bands) were able to cross-react with sera samples from healthy people and DHF patient in endemic area (protein of $31 \mathrm{kDa}$ and $56 \mathrm{kDa}$ ). Sera samples of healthy people from non endemic area were collected from individuals living in subtropical country who have never traveling to tropical countries. They did not show an immunogenic reaction with SGE of Ae. aegypti, and their sera were not able to cross-react with the SG protein extract (Figure 3). This result indicated that people living in endemic areas have specific proteins recognized by antibodies of person who frequently exposed by Ae. aegyptisaliva. These proteins were not found in healthy people from non-endemic areas. Similiar result was reported by Pradines et al. (2007) in which the development of antibody response against $A n$. gambiae and $A e$. aegyptisaliva increased significantly in travelers who transiently exposed to vector bites in tropical area. Cornelie et al., (2007) reported that the development of natural antibodies response for people living in endemic area were due to frequent exposesure to vectors' saliva. Children in malaria endemic areas had developed a spesific lgG response against several proteins of $A n$. gambiae saliva. 


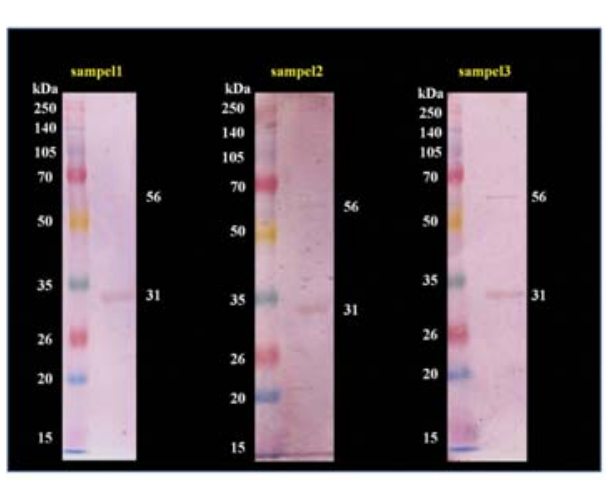

A

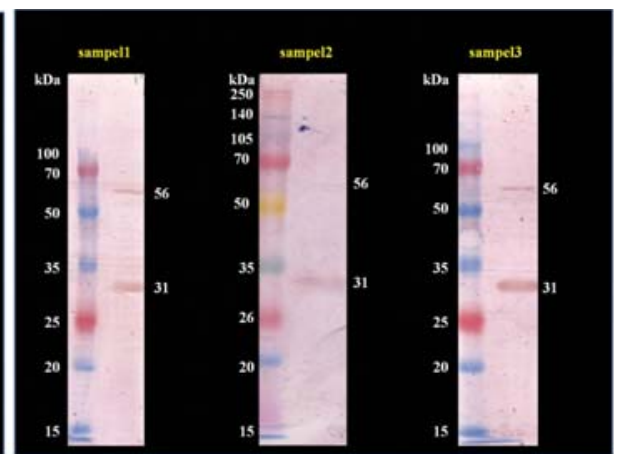

B

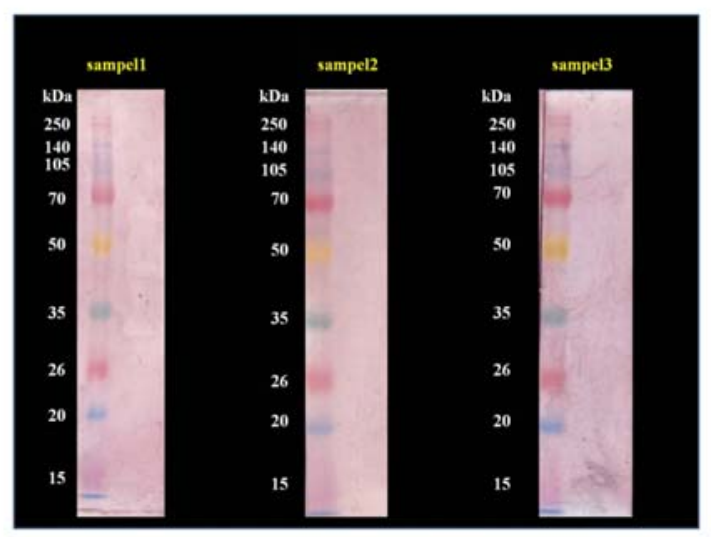

C

Figure 3. Two immunogenic proteins of SGE from Ae. aegypti were identified: 56 and $31 \mathrm{kDa}$ in sera sample from healthy people and DHF patient in endemic area.

(A) healthy people from endemic area , (B) DHF patient (C) healthy people from non endemic area

\section{CONCLUSION}

1. Protein profiles of SGE from Ae. aegypti showed that 15 bands were identified, with different molecular weight ranging from $15 \mathrm{kda}$ up to $255 \mathrm{kda}$. Seven dominant bands were detected i.e $\sim 255,56,42,31,27,26$ and $15 \mathrm{kDa}$.

2. Two immunogenic proteins of SGE Ae. aegypti were detected, the $\sim 31$ and $56 \mathrm{kDa}$. These proteins were able to cross-react with sera samples from people who were previously exposed to mosquitoes bites, and not in people who had not been exposed.

\section{REFERENCES}

Ader, D.B., C. Cellozzi, J. Bisbing, L. Gilmore, V. Gunther, K. Peachman, M. Rao, D. Bawir, W. Sun, and D. Palmer. 2004. Modulation of dengue virus infection of Dendritic cell by Ae. aegypti saliva. Viral Immunology vol. 17 (2): 252-265.

Andrade, B.B., C.R. Teixeira, A. Barral, and M. Barral-Netto. 2005. Haematophagous arthropod saliva and host defense system: a tale of tear and blood. An Acad Bras Cienc. 77(4): 665-693.

Cornelie, S., F. Remouse, S. Doucoure, T. Ndiaye, F. Xavier-Sauvage, D. Boulanger, and F. Simondon. 2007. An insight into immmunogenic proteins of Anopheles gambiae in African cildren. Malaria Journal $6: 75: 1-7$ 
Donovan, M.J., A.S. Messmore, D.S. Scrafford, D.L. Sacks, S. Kamhawi, and M.A. McDowell. 2007. Uninfected mosquito bites confer protection against infection with malaria parasites. Infection and immunity 75 (5): 2523-2530.

Fontaine, A., I. Diouf, N. Bakkali, D. Misse, F. Pages, T. Fusai, C. Rogier, and L. Almeras. 2011. Implication of haematophagous arthropod salivary proteins in host-vector interactions. Parasit \& Vector 4: 187.

Gillespie, R.D., M.L. Mbow, and R.G. Titus. 2000. The Immunomodulatory Factors of Blood Feeding Arthropod Saliva. Parasite Immunol. 22: 319-331.

Juhn, J., U. Naeem-Ullah, B.A.M. Guedes, A. Majid, J. Coleman, P.F.P Pimenta, W. Akram, A.A. James, and O. Marinotti. 2011. Spatial mapping of gene expression in the salivary glands of the Dengue vector mosquito Ae. aegypti. Parasites and Vectors. 41 (1):1-13. Machain-Williams, C., M. Mammen, N. Zeidner, B. Beaty, J. Prenni, A. Nisala, and C. Blair. 2012. Association of human immune response to Ae. aegypti salivary proteins with Dengue disease severity. Parasite Immunol. 34 (1): 15-22.

Orlandi-Pradines, E., L. Almeras, L. Denis de Senneville, S. Barbe, F. Remouse, C. Villard, S. Cornelie, K. Penhoat, A. Pascual, and C. Bourgouin. 2007. Antibody Response Against Saliva Antigens of Anopheles gambiae and Aedes aegypti in Travellers in Tropical Africa. Microbes. Infect. 9: 1454-1462.

Remoue, F., E. Alix, S. Cornelie, and C. Sokhna. 2007. IgE and IgG4 Antibody Responses to Aedes Saliva in African Children. Acta. Tropica.104: 108-115.

Ribeiro, J.M., and I.M. Francischetti. 2003. Role of Arthropod Saliva in Blood feeding: sialome and post-sialome perspective. Ann. Rev. Entomol. 48: 73-78.

Schneider, B., and S. Higgs. 2008. The enhancement of arbovirus transmission and disease by mosquito saliva is associated with modulation of the host immune response. Trans $R$ Soc. Trop. Med. Hyg. 102 (5): 400-408.

Schneider, B., L. Soong, N. Zeidner, and S. Higgs. 2004. Aedes aegyptisalivary gland extracts modulate anti-viral and Th1/Th2 cytokine responses to sindbis virus infection. Viral Immunilogy 17 (4): 565-573.

Valenzuela, J.G., R. Charlab, E.C. Gonzalez, I.K.F. Miranda-Santos, O. Marinotti, I.M. Francischetti, and J.M.C. Ribeiro. 2002. The D7 family of salivary proteins in blood sucking Diptera. Insect Mol Biol 11(2): 149-155.

Wasinpiyamongkol, L., S. Patramool, N. Luplertlop, P. Surasombatpattana, S. Doucoure, M. Seveno, Martial, F. Remouse, E. demettre, J.P. Brizard, and P. Jouin. 2010. Blood feeding and imunogenic aedes aegyptisaliva proteins. Proteomic. 10: 1906-1916.

Waitayakul, A., S. Sumsri, J. Sattabongkot, S. Looareesuwan, L. Cui, and R. Udamsangpetch. 2006. Natural human humoral response to SG proteins of Anopheles mosquotioes in Thailand. Acta Tropica. 98: 66-73. 